\title{
Acute Cadmium Exposure Causes Systemic and Thromboembolic Events in Mice
}

\author{
M. A. FAHIM ${ }^{1}$, A. NEMMAR ${ }^{1}$, S. DHANASEKARAN ${ }^{2}$, S. SINGH ${ }^{1}$, M. SHAFIULLAH ${ }^{2}$, \\ J. YASIN ${ }^{3}$, S. ZIA ${ }^{1}$, M. Y. HASAN ${ }^{2}$ \\ ${ }^{1}$ Department of Physiology, ${ }^{2}$ Department of Pharmacology, ${ }^{3}$ Department of Internal Medicine, \\ Faculty of Medicine, United Arab Emirates University, Al Ain, UAE
}

Received June 28, 2011

Accepted October 17, 2011

On-line December 20, 2011

\section{Summary}

Cadmium (Cd), an environmental and industrial pollutant, poses a potential threat and affects many systems in human and animals. Although several reports on Cd toxicity were presented, the acute effect of $\mathrm{Cd}$ on systemic and thrombotic events was not reported so far. Cd $(2.284 \mathrm{mg} / \mathrm{kg}$ ) or saline (control) was injected intraperitoneally (ip), and the systemic parameters were assessed in mice. Compared to control group, acute intraperitoneal injection of $\mathrm{Cd}$, in mice showed significant quickening of platelet aggregation $(P<0.001)$ leading to pial cerebral thrombosis. Likewise, $C d$ exposure caused a significant increase in white blood cell numbers $(P<0.05)$ indicating the occurrence of systemic inflammation. Also, alanine aminotransferase (ALT) $(P<0.05)$ and creatinine $(P<0.01)$ levels were both significantly increased. Interestingly, the superoxide dismutase activity was significantly decreased in $\mathrm{Cd}$ treated group compared to control group $(P<0.001)$, suggesting the occurrence of oxidative stress. We conclude that the $\mathrm{Cd}$ exposure in mice causes acute thromboembolic events, oxidative stress and alter liver and kidney functions.

\section{Key words}

Cadmium • Thrombosis • Liver • Kidney • Toxicology

\section{Corresponding author}

Mohamed Abdelmonem Fahim, United Arab Emirates University, Faculty of Medicine and Health Sciences, Department of Physiology, P.O. Box 17666, Al Ain, UAE. Fax: +971 37671966.

E-mail: m.fahim@uaeu.ac.ae

\section{Introduction}

Cadmium (Cd), an ubiquitous heavy metal and an environmental pollutant, found in soil, water and air. It is one of the key component abundantly present in nickelcadmium (Ni-Cd) battery wastes, cigarette smoke, blue paint pigments, copper smelters etc. (Svoboda et al. 2000, Kala et al. 1996). On inhalation or ingestion, $\mathrm{Cd}$ has been found to pose a potential threat and affects many systems in human and animals as a consequence of environmental and industrial pollution. $\mathrm{Cd}$ has high influence in inducing toxicity over lungs, skeletal muscles by causing edematous emphysema, osteoporosis and osteomalacia, brain edema and hemorrhage and blood-brain barrier disruption (Patra et al. 2011, Shukla et al. 1996). Carcinogenic damage was observed in the lungs in Cdexposed workers (Järup et al. 1998). Cd may also contribute towards endothelial damage either directly by interacting with the endothelium or by inducing the generation of reactive oxygen species in endothelial and inflammatory cells (Järup et al. 1998).

It has been demonstrated that $\mathrm{Cd}$ can inhibit protein synthesis completely to facilitate apoptotic cell death (Jung et al. 2008, Ivanov et al. 2002, SzusterCiesielska et al. 2000). Moreover, Cd induces cell death in vivo and in vitro at varied concentrations from 1 to $300 \mu \mathrm{M}$ (Shih et al. 2004). Cd has been described as a pro-necrotic metal ion (Kim et al. 2003, López et al. 2003).

$\mathrm{Cd}$ concentrates in the kidney, particularly inducing proteinuria and renal dysfunction; it is associated with hypertension (Ding et al. 2011). 
Cadmium has high affinity for sulfhydryl (-SH) groups, inactivating numerous enzymatic reactions, amino acids, and sulfur-containing antioxidants including $\mathrm{N}$-acetylcysteine, alpha-lipoic acid and glutathione with subsequent decreased oxidant defense and increased oxidative stress. Long-term exposure to $\mathrm{Cd}$ increases lipid peroxidation and causes inhibition of SOD activity indicating oxidative damage in liver, kidney and testes (Patra et al. 2011).

Studies on $\mathrm{Cd}$ induced intoxication which caused severe platelet aggregation (PA) and thrombosis in testes and epididymis (Francavilla et al. 1981) have been demonstrated. The tendency to increase the leukocyte adhesion in male subjects has also been reported (Tubek et al. 2010). However, the possible acute effect of $\mathrm{Cd}$ on cerebral microvessel thrombosis and its link to systemic inflammation and oxidative stress has not been reported so far.

Consequently, the aim of the present studies is to investigate the effect of $\mathrm{Cd}$ on cerebral microvessel thrombosis, systemic inflammation and oxidative stress, and its effect on liver and kidney.

\section{Methods}

\section{Animals and treatment}

This project was reviewed and approved by the Institutional Review Board of the United Arab Emirates University, Faculty of Medicine and Health Sciences, and experiments were performed in accordance with protocols approved by the Institutional Animal Care and Research Advisory Committee.

Adult male mice, TO strain, weighing 30-35 g, each group consisting between six to ten animals from a colony maintained at our animal house facility were used. Animals were group-housed in a temperature maintained $\left(22 \pm 2{ }^{\circ} \mathrm{C}\right)$ and a light/dark cycle (12/12 h) environment. They had access to standard pelleted diet and water ad libidum. Except for their intended treatment all animals were handled in the same manner. All animal treatment procedures met both the NIH and Institutional Animal Ethics Committee guidelines.

$\mathrm{Cd}$, in the form of cadmium chloride hemipentahydrate (Sigma Chemicals) was dissolved in normal saline to administer the dose of $2.284 \mathrm{mg} / \mathrm{kg}$ body weight as a single bolus $(0.2 \mathrm{ml})$ injection, intraperitoneally (ip), at one hour before experimentation. Control mice received normal saline only.

\section{Experimental pial cerebral thrombosis model}

In vivo pial cerebral microvessel thrombogenesis was assessed as previously described (Fahim et al. 2011, Nemmar et al. 2009). One hour after the treatment with $\mathrm{Cd}$ or saline, mice were anaesthetized with urethane (25\%, $0.1 \mathrm{ml} / 10 \mathrm{~g}$ b.w., ip) and trachea was intubated. Cerebral microvessels were exposed after performing craniotomy on the anaesthetized mice on the left side of the head, with the aid of a microdrill and dura was carefully removed. Average body temperature fell to $33.2 \pm 0.6^{\circ} \mathrm{C}$ after anesthesia and surgery. The body temperature was stabilized at $37{ }^{\circ} \mathrm{C}$ with the help of an infra-red lamp and monitored with a rectal thermoprobe (Physitemp Model RET-3). The preparation was kept moist with artificial cerebrospinal fluid (ACSF). Composition of the ACSF used was (mM): $\mathrm{NaCl} 124$, $\mathrm{KCl} 5, \mathrm{NaH}_{2} \mathrm{PO}_{4} 3, \mathrm{CaCl} 2.5, \mathrm{MgSO}_{4}, 2.4, \mathrm{NaHCO}_{3} 23$, and glucose 10; $\mathrm{pH}$ 7.3. Only untraumatized preparations were used and those showing trauma to either microvessels or underlying brain tissue were discarded. The closed circuit set up used consisted of: a fluorescence microscope (Olympus, BH-2), a colour video camera (JVC, TK-890E), a VHS-VCR (JVC, BR-S600E) and a television monitor (JVC, TM-1500PS). All microscopic observations utilized a fiber-optic light source and were made using a $4 \mathrm{x}$ objective lens and a $10 \mathrm{x}$ eye piece. Total magnification of the observed field, from the microscope stage to the television monitor was $\mathrm{x} 250$.

Sodium fluorescein $(2 \%, 0.1 \mathrm{ml} / 10 \mathrm{~g}$, iv.) was injected via the tail vein. Sodium fluorescein was allowed to circulate in the body for 30 seconds before high intensity mercury light was switched on. The combination of light and fluorescein dye produces a free radical which injures the endothelium of the microvessel's lumen. This in turn, causes platelets to adhere at the sites of endothelial damage and then aggregate. The aggregates fluoresced and were readily visible as they adhered to the damaged endothelium. Platelet aggregates grow in size until complete vascular occlusion. The time when the first observable aggregate appeared (time to first aggregate) and until full vascular occlusion (time to flow stop) in both venules and arterioles were measured in seconds with four stop watches. The time to aggregate growth was calculated as the difference between the time to first aggregate and the time to flow stop. Diameters before insult and after full vascular occlusion were measured in control and treated mice from video recordings and changes were calculated. All events were video taped for analysis and 
measurement of microvessel diameter changes.

\section{Blood collection and complete blood count analysis}

Another group of animals was subjected to $\mathrm{Cd}$ or saline treatment at the dose mentioned earlier. One hour after the treatment, the animals were anesthetized intraperitoneally with sodium pentobarbital $(45 \mathrm{mg} / \mathrm{kg})$, and then blood was drawn from the inferior vena cava in EDTA (4\%). Part of the blood was used for platelets and white blood cells (WBC) counts using an ABX VET ABC Hematology Analyzer with a mouse card (ABX Diagnostics, Montpellier, France). The remaining blood was centrifuged for $15 \mathrm{~min}$ at $4{ }^{\circ} \mathrm{C}$ at $900 \times \mathrm{g}$, and the plasma obtained was stored at $-80^{\circ} \mathrm{C}$ pending analysis.

Liver function and lactate dehydrogenase (LDH) estimation

Liver function tests included alanine aminotransferase (ALT) and aspartate aminotransferase (AST) estimation in plasma. The ALT and AST were measured using standard laboratory methods using LX20 multiple automated analyzer (Beckman Coulter, CA, USA) with their estimation kit. The LDH was measured using commercial kits (Sigma Chemical, St. Louis, MO, USA) which determine the conversion of lactate to pyruvate in the presence of LDH with equivalent lessening of NAD. The formation of NADH from the above reaction can show a difference when measured in absorbance at $340 \mathrm{~nm}$.

Creatinine, blood urea nitrogen (BUN) and superoxide dismutase (SOD) estimation

The creatinine and BUN were measured spectrophotometrically using commercial kits purchased from Human $\mathrm{GmbH}$ (Wiesbaden, Germany).

The SOD, a free radical scavenging enzyme, was performed by the photo oxidation method and measured using a commercial kit (Cayman Chemicals, Michigan, USA) (Nemmar et al. 2010).

\section{Statistical analysis}

Data was statistically analyzed using the unpaired samples Student's t-test (Graphpad Prism®). Tests were carried out to detect differences among the means of the each groups and P-value $<0.05$ was considered significant.

\section{Results}

\section{Effect of cadmium on pial cerebral thrombosis}

The effects of $\mathrm{Cd}$ treatment on the time required for PA and for full occlusion in pial microvessels are shown in Figure 1. In our results, the animals treated with $\mathrm{Cd}$, the onset time for PA in both venules and arteriole showed very significant quickening $(P<0.001)$ when compared to control group. The onset time of aggregation in arteriole was found to be $60 \%$ whereas in venule a $20 \%$ quicker response was observed when compared to control group (Fig. 1A). This indicates an increased susceptibility to thrombosis in cadmium exposed animals. Subsequently, the total occlusion in the arterioles but not the venules showed a significant shortening in time $(P<0.001)$ when compared to the control. (Fig. 1B). The vascular diameter changes throughout the photochemical insult among the both groups were within a very narrow range and not statistically different.

\section{Blood collection and complete blood count analysis}

Estimation of erythrocytes, leucocytes, haemoglobin and platelets were done in $\mathrm{Cd}$ and saline treated groups. Results of the blood cells count showed no significant changes in the erythrocyte numbers and total haemoglobin concentration. The platelet counts showed an insignificant decrease in their numbers in $\mathrm{Cd}$ treated mice (Fig 2). Whilst in leucocytes count, the cadmium treated group exhibited a statistically significant rise in the number $(P<0.05)$ which was overall doubled suggesting a systemic inflammatory response as the consequence of the cadmium toxicity.

\section{Liver function and LDH estimation}

The indicators of the liver function were assessed by estimating AST and ALT in plasma of the cadmium treated mice. The ALT level increased significantly $(P<0.01)$ suggesting that the acute cadmium treatment causes alteration in the liver function. Our results showed the cadmium treated group insignificantly increased the AST level $(P=\mathrm{NS})$ when compared to the control (Fig. 3).

LDH estimation is widely performed to estimate the cytotoxicity or the cell viability. Our data showed an increase in LDH activity following Cd exposure (Fig. 4). However, the increase failed to reach statistical significance. 
৫ Venule $1^{\text {st }}$ Aggregation
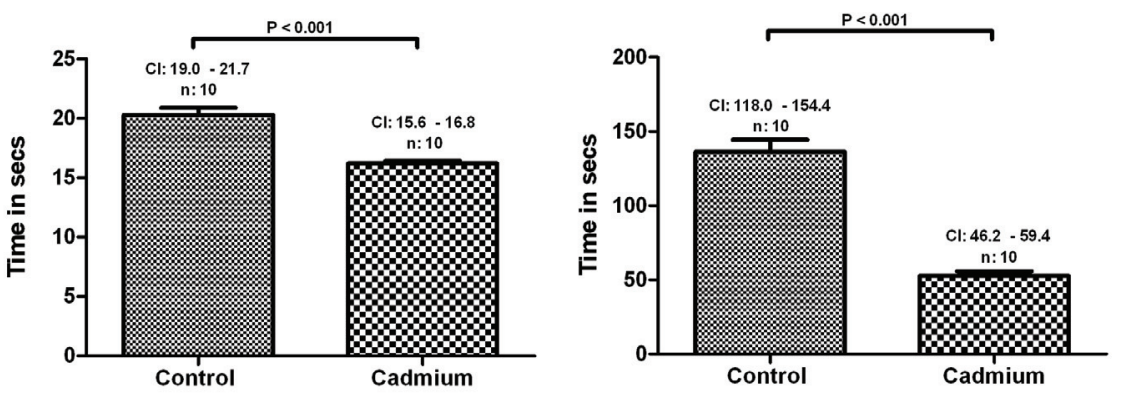

B

Arterial Flow Stop

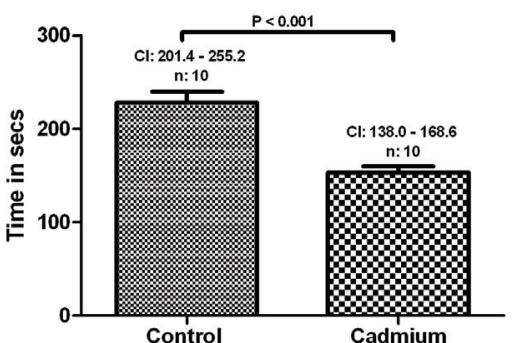

Control

\section{Arterial $1^{\text {st }}$ Aggregation}

\section{Venule Flow Stop}

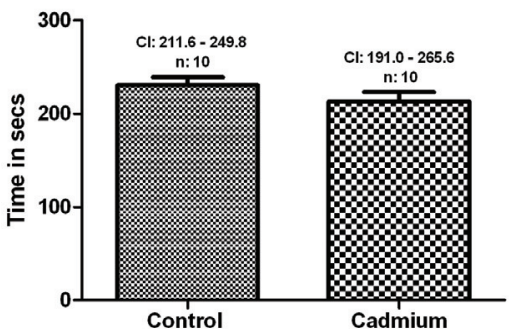

B
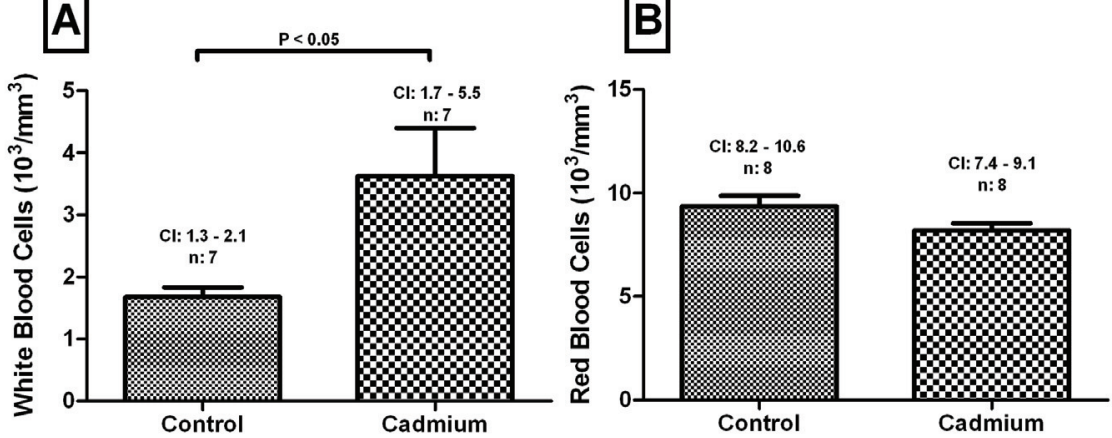

Fig. 1. Effect of $\mathrm{Cd}$ exposure on cerebro vascular thrombosis in which the start of the aggregation in the venule and arteriole (Panel A) and the complete flow stop after adequate aggregation in venule and arteriole (Panel B) in saline treated control and the cadmium treated animals. Data in bar graph shown are mean \pm SEM, Confidence Interval (CI), number of samples $(n) ; P<0.001$.
Fig. 2. Effect of $\mathrm{Cd}$ exposure on the complete blood cell counts. A - Erythrocytes, B - Leucocytes, C - Total hemoglobin and D Platelets - in saline treated control and the cadmium treated animals; $* P<0.05$.

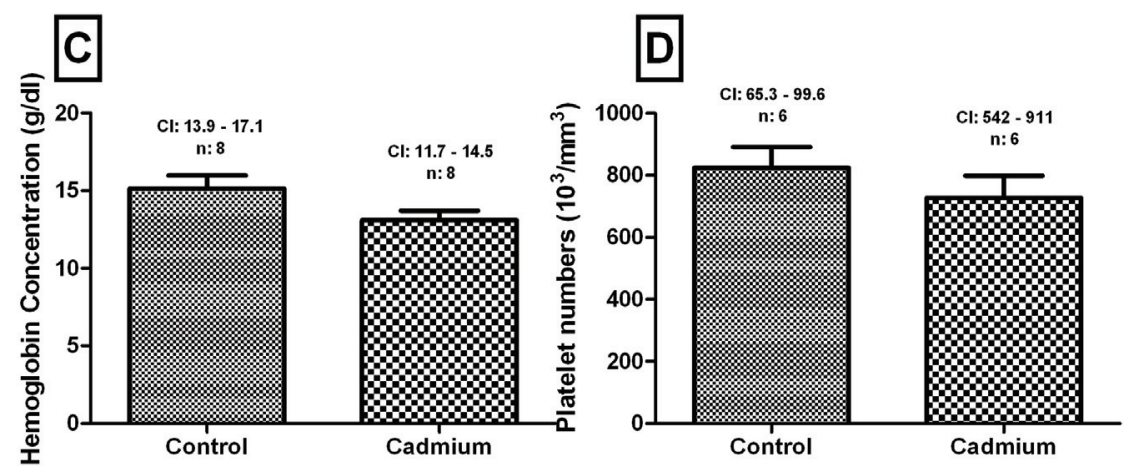



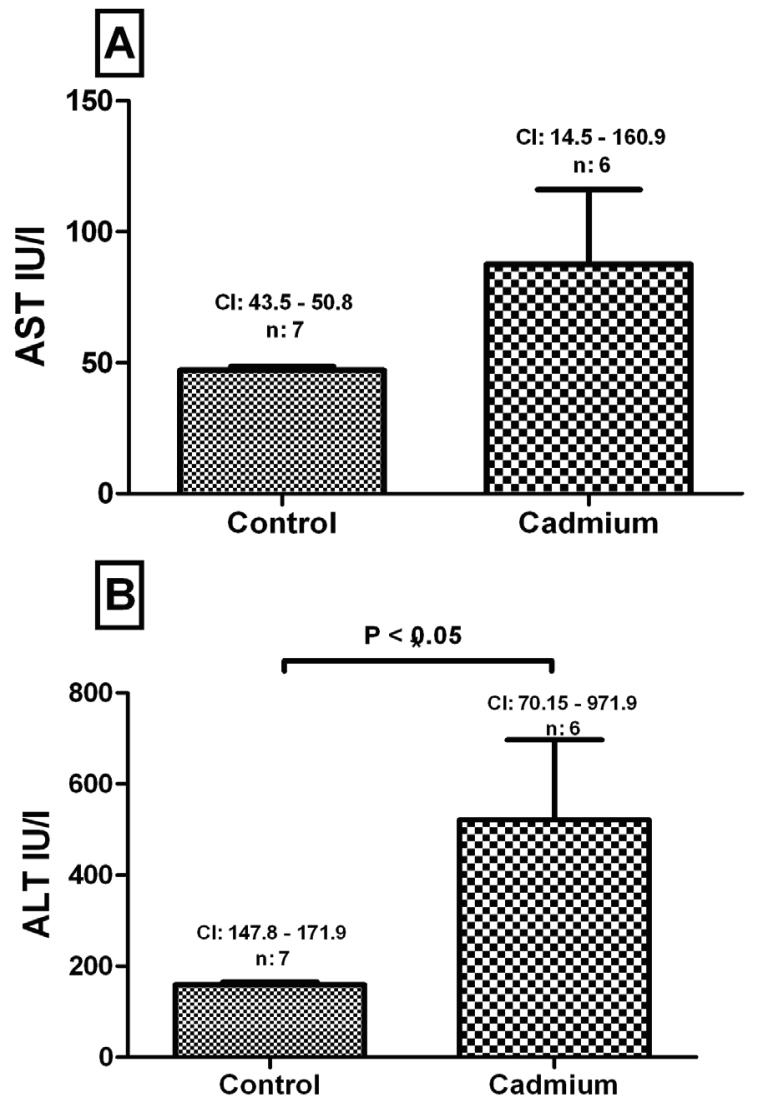

Fig. 3. Effect of $\mathrm{Cd}$ treatment on the liver enzyme levels. A - shows AST and B - ALT - in saline control and cadmium treated animals. Data in bar graph shown are mean \pm SEM, Confidence Interval (CI), number of samples (n); $P<0.01$.

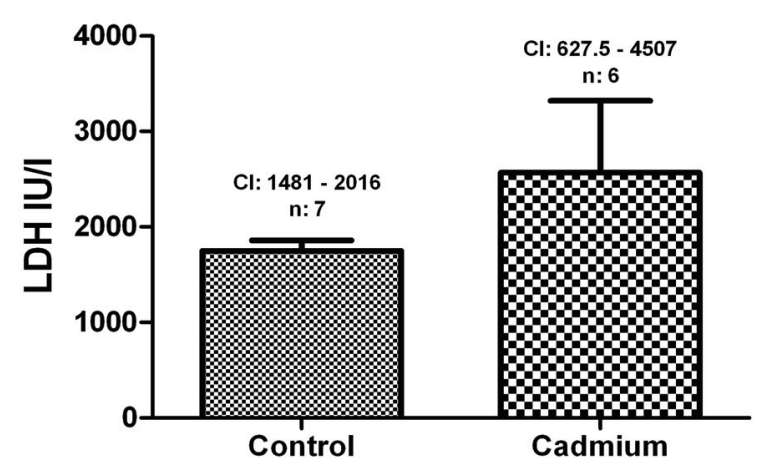

Fig. 4. Effect of $\mathrm{Cd}$ exposure on the LDH levels in saline control and cadmium treated animals. Data in bar graph shown are mean \pm SEM, Confidence Interval (CI), number of samples $(n)$.

\section{Creatinine, BUN and SOD estimation}

We measured the creatinine and BUN to determine the toxicity induced by cadmium in kidney functions. Our results showed that creatinine level has significantly increased (1.5 fold) over the control group $(P<0.01)$ suggesting the role of cadmium in kidney damage. However, the BUN data showed no changes between the two groups (Fig. 5).
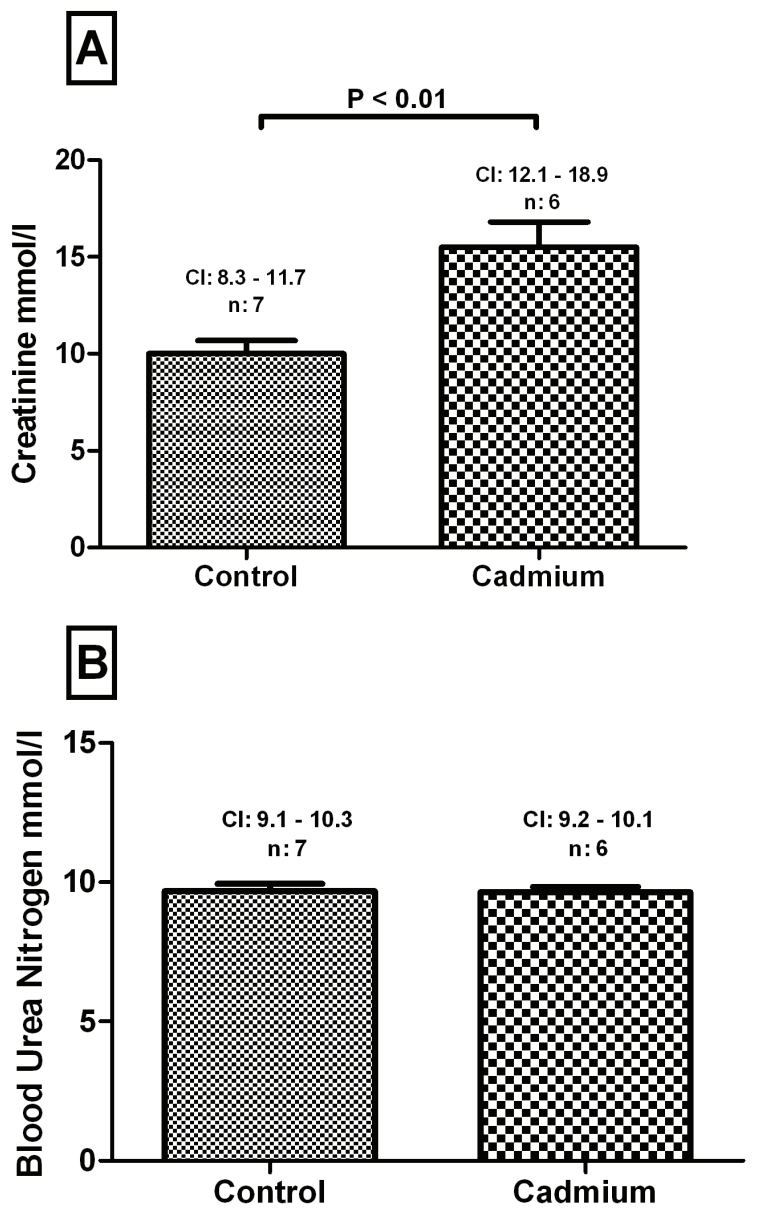

Fig. 5. Effect of $\mathrm{Cd}$ exposure on the creatinine (Panel A) and BUN levels (Panel B) in the control or cadmium treated animals. Data in bar graph shown are mean \pm SEM, Confidence Interval (CI), number of samples (n); $P<0.01$.

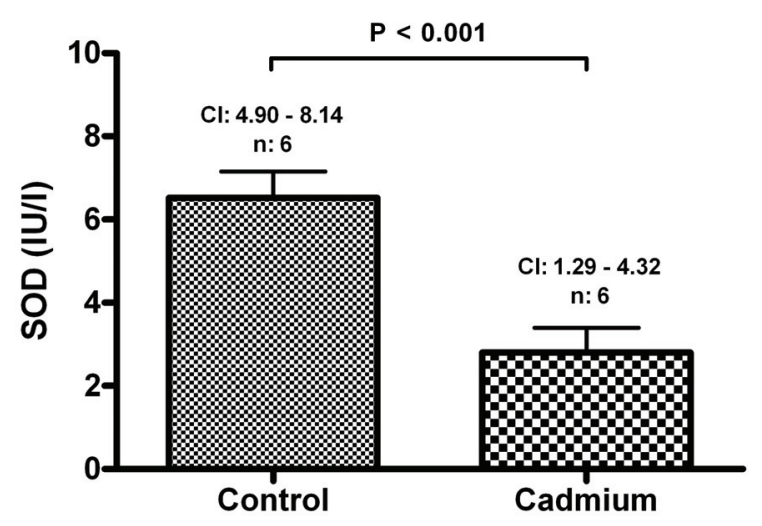

Fig. 6. Effect of Cd treatment on SOD levels in the control or cadmium treated animals. Data in bar graph shown are mean \pm SEM, Confidence Interval (CI), number of samples $(n) ; P<0.001$.

Our estimation of SOD in the plasma in $\mathrm{Cd}$ treated animals showed their levels in the $\mathrm{Cd}$ treated group decreased significantly $(P<0.01)$ at the dose tested (Fig. 6). 


\section{Discussion}

In our present study, we have showed that $\mathrm{Cd}$, when administered at a single bolus injection of $2.284 \mathrm{mg} / \mathrm{kg}$, ip, induced the thrombosis in the cerebral micro vessels and increased the total WBC, ALT and creatinine levels. The $\mathrm{Cd}$ treatment also showed an increase, although insignificant, in the levels of AST and LDH. These changes imply that, at this acute dose tested, the Cd can significantly play a role in the PA to induce thrombosis and induce the systemic inflammation causing damages including the liver and kidney. At the same time, we have found the Cd treatment reduced the SOD levels which possibly could imply that the oxidative stress could be a factor to influence these changes.

The toxic levels of $\mathrm{Cd}$ affects kidneys (Humphreys 1991), haemopoietic system and liver (Shim et al. 2008). Renal and hepatic damage caused when exposed by $\mathrm{Cd}$ is more toxic than lead (Humphreys 1991). There is still much to find out about the mechanisms of action, biomarkers of critical effects and ways to protect the health risks induced by $\mathrm{Cd}$. In our thromboembolic studies, $\mathrm{Cd}$ treatment reduced the time required for both the appearance of the first aggregate and the time for full occlusion in pial arterioles. In-vitro study on $\mathrm{Cd}$ stimulates adenylate cyclase and inhibits phosphodiesterase (PDE) activity with a decrease in the rate of PA (Kumar and Bhattacharya 2000). However, our result with in-vivo treatment of $\mathrm{Cd}$ which showed quickening of PA is in disagreement with the in-vitro studies by the previous authors at this stage.

Circulating platelets do not normally adhere to the endothelial cells of the vascular wall or aggregate, except when activated or when damage to the endothelium is attained. When such damage occurs, the aggregates are induced which will lead to formation of thrombosis. The development of thrombi in the circulatory system would result in reduced blood delivery and consequently, in tissue hypoxia/ischemia (Geys et al. 2008). Francavilla et al. (1981) reported the quickening of the thrombosis induced by $\mathrm{Cd}$ in testes and epidydemis in rats. In concurrence with this previous study, our results show quickening of PA activity in pial cerebral vasculature during in-vivo treatment of $\mathrm{Cd}$ in mice. The same authors also demonstrated the variability of in-vitro and in-vivo treated $\mathrm{Cd}$ on $\mathrm{PA}$ activity to induce thrombosis. Likewise, our results are also in line with the previous report by Järup et al. (1998) who published the correlation of the endothelial damage either directly induced by $\mathrm{Cd}$ on endothelium or indirectly by releasing the reactive oxygen species in endothelial and inflammatory cells. These direct or indirect effects are mediating the quickening of thrombosis, as found in our studies. This was well supported by our other estimations of SOD, WBC, and LDH and discussed in this paper which shows significant change in all their levels. Clearly these parameters are the indicators of oxidative stress or systemic inflammatory responses by tissues.

As Cd primarily accumulates in the liver, it becomes more important target organ for damage (Świergosz-Kowalewska 2001). Reliability of the hepatocellular function can be attained by quantifying the enzymes ALT and AST. Changes in the levels of these enzymes reveal the variations in the cell membrane functions including the alteration in the permeability which leads to cell damage (Shih et al. 2004). Among these two enzymes, measurement of ALT is considered as a good marker to indicate the liver damage particularly in animal species (Haschek et al. 2002). In our experiments we have demonstrated the acute administration of $\mathrm{Cd}$ remarkably elevate the levels of ALT and AST (Fig. 3) indicating the severe damage to liver.

LDH is an index of the cell damage including hepatotoxicity and the endothelial disruption in blood vessels. We observed an increase of $\mathrm{LDH}$, although insignificant, is suggestive of the beginning of the cytolysis, which is a possible indication of membrane damage including the endothelial membranes in blood vessels. This disruption of endothelial membrane, directly or indirectly, as reported earlier by Järup et al. (1998), induces the generation of reactive oxygen species in endothelial cells which are one among the factor responsible for inducing $\mathrm{PA}$.

$\mathrm{Cd}$ is a well-known nephrotoxic agent. $\mathrm{Cd}$ induced renal tubular dysfunction and decreased glomerular filtration leading to renal failure was reported (Kido et al. 1990, Ding et al. 2011). Recent study reported that women who exposed even to a lower level of $\mathrm{Cd}$ contracted the tubular and glomerular kidney effects (Akesson et al. 2005). The kidney lesions induced by cadmium are irreversible and hence the exposure to Cd should be minimized (Järup et al. 1995). In line with previously published reports, our results showed rapid increase of creatinine suggesting the severe damage in glomeruli function.

$\mathrm{Cd}$ has been shown to induce oxidative stress which is a major cause of atherosclerosis. Oxidative stress arises from an imbalance between the production of 
free radicals and physiological antioxidant capability (Patra et al. 2011). Estimation of SOD is an important indicator of oxidative stress. To determine whether systemic oxidative stress was induced by $\mathrm{Cd}$, we measured SOD levels in plasma. Our results showed a significant fall in levels of SOD indicating a potential damage caused by $\mathrm{Cd}$. Long term ingestion of $\mathrm{Cd}$ has been demonstrated to inhibit the SOD levels in liver, kidney and testis (Patra et al. 2011). Our findings provide an evidence of $\mathrm{Cd}$ to be a key factor for inducing oxidative stress thereby inducing the PA. The antioxidants like vitamin $\mathrm{C}$ could have a protective effect on the damage caused by $\mathrm{Cd}$ on the PA. We have recently reported that the vitamin $\mathrm{C}$ and $\mathrm{E}$ pre-treatment protects against the nicotine induced thrombosis in mice (Fahim et al. 2011).

In conclusion, $\mathrm{Cd}$ induced acceleration in thromboembolic formation leading to quick occlusion of the vascular tissues are in concurrence with the changes in the levels of liver enzymes, increase in the leucocyte levels. The results summarized above show the high implication of $\mathrm{Cd}$ against the $\mathrm{PA}$, liver and kidney dysfunction. Further studies are essential to determine the mechanisms behind these observations. Our findings add more significant data, particularly on the thrombotic occurrences to the toxicological effects induced by cadmium.

\section{Conflict of Interest}

There is no conflict of interest.

\section{Acknowledgements}

We would like to thank Faculty of Medicine and Health Sciences, UAE University, Al Ain for funding this project.

\section{References}

AKESSON A, LUNDH T, VAHTER M, BJELLERUP P, LIDFELDT J, NERBRAND C, SAMSIOE G, STRÖMBERG U, SKERFVING S: Tubular and glomerular kidney effects in Swedish women with low environmental cadmium exposure. Environ Health Perspect 113: 1627, 2005.

DING X, ZHANG Q, WEI H, ZHANG Z: Cadmium-induced renal tubular dysfunction in a group of welders. Occup Med (Lond) 61: 277-279, 2011.

FAHIM MA, NEMMAR A, SINGH S, HASSAN MY: Antioxidants aleviate nicotine-induced platelet aggregation in cerebral arterioles of mice in vivo. Physiol Res 60: 695-700, 2011.

FRANCAVILLA S, MOSCARDELLI S, FRANCAVILLA F, CASASANTA N, PROPERZI G, MARTINI M, SANTIEMMA V: Acute cadmium intoxication: influence of cyproterone acetate on the testis and epididymis of the rat. Arch Androl 6: 1-11, 1981.

GEYS J, NEMMAR A, VERBEKEN E, SMOLDERS E, RATOI M, HOYLAERTS M. F, NEMERY B, HOET PHM: Acute toxicity and prothrombotic effects of quantum dots: impact of surface charge. Environ Health Perspect 116: 1607-1613, 2008.

HASCHEK W, ROUSSEAUX C, WALliG M: Handbook of Toxicologic Pathology. Academic Press, San Diego, 2002.

HUMPHREYS DJ: Effects of exposure to excessive quantities of lead on animals. $\mathrm{Br}$ Vet $J$ 147: 18-30, 1991.

IVANOV L, LESAUSKAITE V, SADAUSKIENE I, STAPULIONIS R: Acute cadmium exposure changes protein synthesis in mice liver and activates apoptosis. Biomedicine 2: 41-45, 2002.

JÄRUP L, PERSSON B, ELINDER CG: Decreased glomerular filtration rate in solderers exposed to cadmium. Occup Environ Med 52: 818-822, 1995.

JÄRUP L, BERGLUND M, ELINDER CG, NORDBERG G, VAHTER M: Health effects of cadmium exposure a review of the literature and a risk estimate. Scand J Work Environ Health 24 (Suppl 1): 1-51, 1998.

JUNG YS, JEONG EM, PARK EK, KIM YM, SOHN S, LEE SH, BAIK EJ, MOON CH: Cadmium induces apoptotic cell death through p38 MAPK in brain microvessel endothelial cells. Eur J Pharmacol 578: 11-18, 2008.

KALA P, NINANSKÁ M, BEVILAQUA D, STAKOVÁ I: Concentrations of mercury, copper, cadmium and lead in fruiting bodies of edible mushrooms in the vicinity of a mercury smelter and a copper smelter. Sci Total Environ 177: 251-258, 1996. 
KIDO T, NOGAWA K, ISHIZAKI M, HONDA R, TSURITANI I, YAMADA Y, NAKAGAWA H, NISHI M: Longterm observation of serum creatinine and arterial blood $\mathrm{pH}$ in persons with cadmium-induced renal dysfunction. Arch Environ Health 45: 35-41, 1990.

KIM SC, CHO MK, KIM SG: Cadmium-induced non-apoptotic cell death mediated by oxidative stress under the condition of sulfhydryl deficiency. Toxicol Lett 144: 325-336, 2003.

KUMAR SV, BHATTACHARYA S: In vitro toxicity of mercury, cadmium, and arsenic to platelet aggregation: influence of adenylate cyclase and phosphodiesterase activity. In Vitr Mol Toxicol 13: 137-144, 2000.

LÓPEZ E, FIGUEROA S, OSET-GASQUE MJ, GONZÁLEZ MP: Apoptosis and necrosis: two distinct events induced by cadmium in cortical neurons in culture. Br J Pharmacol 138: 901-911, 2003.

NEMMAR A, AL-SALAM S, DHANASEKARAN S, SUDHADEVI M, ALI BH: Pulmonary exposure to diesel exhaust particles promotes cerebral microvessel thrombosis: protective effect of a cysteine prodrug 1-2oxothiazolidine-4-carboxylic acid. Toxicology 263: 84-92, 2009.

NEMMAR A, AL-SALAM S, ZIA S, DHANASEKARAN S, SHUDADEVI M, ALI BH: Time-course effects of systemically administered diesel exhaust particles in rats. Toxicol Lett 194: 58-65, 2010.

PATRA RC, RAUTRAY AK, SWARUP D: Oxidative stress in lead and cadmium toxicity and its amelioration. Vet Med Int 2011: 457327, 2011.

SHIH CM, KO WC, WU JS, WEI YH, WANG LF, CHANG EE, LO TY, CHENG HH, CHEN CT: Mediating of caspase-independent apoptosis by cadmium through the mitochondria-ROS pathway in MRC-5 fibroblasts. J Cell Biochem 91: 384-397, 2004.

SHIM JY, SHIN H, HAN JG, PARK HS, LIM BL, CHUNG KW, OM AS: Protective effects of Chlorella vulgaris on liver toxicity in cadmium-administered rats. J Med Food 11: 479-485, 2008.

SHUKLA A, SHUKLA GS, SRIMAL R: Cadmium-induced alterations in blood- brain barrier permeability and its possible correlation with decreased microvessel antioxidant potential in rat. Hum Exp Toxicol 15: 400-405, 1996.

SVOBODA L, ZIMMERMANNOVÁ K, KALA P: Concentrations of mercury, cadmium, lead and copper in fruiting bodies of edible mushrooms in an emission area of a copper smelter and a mercury smelter. Sci Total Environ 246: 61-67, 2000.

ŚWIERGOSZ-KOWALEWSKA R: Cadmium distribution and toxicity in tissues of small rodents. Microsc Res Tech 55: 208-222, 2001.

SZUSTER-CIESIELSKA A, LOKAJ I, KANDEFER-SZERSZEŃ M: The influence of cadmium and zinc ions on the interferon and tumor necrosis factor production in bovine aorta endothelial cells. Toxicology 145: 135-145, 2000.

TUBEK S, BUNIO A, SZYGUŁA R, TUBEK A: Frequency of hospitalization for angina pectoris, stroke, and peripheral venous thrombosis and its relationship to elements in rainwater in Opole Voivodship, Poland, during 2000-2002. Biol Trace Elem Res 133: 243-250, 2010. 